\title{
Fatal thrombosis in complex cardiac surgery without deep hypothermic circulatory arrest in the setting of standard-of-care heparinization: Status quo and directions for further research
}

\author{
John G. T. Augoustides, MD, FASE, Philadelphia, Pa
}

$\mathrm{F}$ atal thrombosis in complex cardiac surgery without deep hypothermic circulatory arrest was highlighted in a case report of biventricular assist device placement complicated by aortic cannula thrombosis and subsequent fatal cerebral infarction. ${ }^{1}$ The risk factors identified in this case were aprotinin exposure and stasis of blood in the aortic cannula after protamine administration. Despite standard-of-care heparinization, this syndrome has persisted, as evidenced by a series of case reports $(n=4$ : 1996-2006). ${ }^{1-4}$ The purpose of this brief communication is to review this cumulative case series to guide further investigation. The literature search was conducted with PubMed (last entry May 31, 2007) with the following search terms: thrombosis and cardiac surgery; aprotinin and thrombosis in cardiac surgery; aminocaproic acid and thrombosis in cardiac surgery; tranexamic acid and thrombosis in cardiac surgery; and factor VIII and thrombosis in cardiac surgery. One case report was excluded inasmuch as it was later included as part of a larger case series. ${ }^{3}$

As a group, the published case reports of fatal thrombosis in complex cardiac surgery without deep hypothermic circulatory arrest can be summarized as follows ${ }^{1-4}$ :

1. The cohort total is 12 patients ( 7 men; 5 women).

2. The age range is 19 to 69 years.

3. All patients had antifibrinolytic therapy (11 aprotinin; 1 aminocaproic acid).

4. Anticoagulation was with bolus heparin titrated to maintain the activated clotting time (ACT) greater than 500 seconds (10 kaolin-based ACT; 1 celite-based ACT; 1 unspecified activator).

5. The type of complex cardiac surgery was as follows: valve replacement for infective endocarditis in 2 patients; ventricular assist device implantation in 6 patients; heart transplantation in 2 patients; and left ventricular reconstruction with a mitral valve procedure in 2 patients.

6. In 11 of 12 patients, circulatory collapse resulting from intravascular thrombosis began within 60 minutes of sep-

From the Cardiothoracic Section, Anesthesiology and Critical Care, Hospital of the University of Philadelphia, Philadelphia, Pa.

Received for publication June 6, 2007; accepted for publication June 21, 2007.

Address for reprints: John G. T. Augoustides, MD, FASE, Assistant Professor, Cardiothoracic Section, Anesthesiology and Critical Care, Dulles 680, Hospital of the University of Philadelphia, 3400 Spruce St, Philadelphia, PA 19104-4283 (E-mail: yiandoc@ hotmail.com).

J Thorac Cardiovasc Surg 2007;134:1053-4

$0022-5223 / \$ 32.00$

Copyright $\odot 2007$ by The American Association for Thoracic Surgery doi:10.1016/j.jtcvs.2007.06.014 aration from cardiopulmonary bypass and protamine administration. In the remaining patient, gross thrombus was seen in the aortic cannula and ascending aorta within 60 minutes of protamine administration.

7. The circulatory collapse was in all cases severe, requiring reheparinization and return to cardiopulmonary bypass. The predominant hemodynamic pattern was right ventricular failure with acute pulmonary hypertension (10/11 cases).

8. The degree of thrombosis in all cases was clinically significant and all cardiovascular compartments were at risk: venous, arterial, capillary, and cardiac chambers. In 3 of 12 patients, the thrombus formation was evident on visual inspection. In 9 of 12, autopsy demonstrated diffuse microthrombi.

9. Fibrinolysis with tissue plasminogen activator was used as emergency rescue therapy in 2 patients. In 1 patient, this resulted in clinical improvement that allowed transfer to the intensive care unit. Unfortunately, this patient died subsequently of massive bleeding.

10. The syndrome has a $100 \%$ mortality.

11. In 1 patient, antibodies were detected that activated platelets via Fc-receptor IIa. In 11 of 12 patients, investigation for coagulation abnormalities was not reported.

This case series is limited by the small sample size and suggests more questions than answers. Despite these limitations, the following observations may serve to direct future study of this fatal syndrome:

1. A global case registry would boost sample size and thus facilitate further analysis.

2. Preoperative hypercoagulable states may participate in the pathophysiology of the syndrome.

3. In the presence of an antifibrinolytic, standard-of-care heparinization for complex cardiac surgery in adults does not protect all patients from serious intraoperative thrombotic complications.

4. To date, this syndrome has not been reported in association with tranexamic acid or recombinant factor VIII. ${ }^{5}$

5. When a case occurs, the index patient and family should be investigated for concomitant hypercoagulable states.

Despite the advances in complex cardiac surgery without deep hypothermic circulatory arrest, there are still patients at risk for lethal vascular thrombosis. Further investigation is a priority to delineate the pathogenesis and effective therapy for this rare but important syndrome.

\section{References}

1. Gitter R, Alivizianos P, Capehart J, Ramsay M, Jett GK. Aprotinin and aortic cannula thrombosis. J Thorac Cardiovasc Surg. 1996;112:537-8.

2. Augoustides JG, Kilbaugh T, Harris H, Glick JH, Acker M, Savino JS. Fatal thrombosis after mitral valve replacement for endocarditis: apro- 
tinin and disseminated intravascular coagulation. Anesthesiology. 2006; 104:213.

3. Cooper JR, Abrams J, Frazier OH, Radovancevic R, Radovancevic B, Bracey AW, et al. Fatal pulmonary microthrombi during surgical therapy for end-stage heart failure: possible association with antifibrinolytic therapy. J Thorac Cardiovasc Surg. 2006;131:963-8
4. Kottenberg-Assenmacher E, Volbracht L, Jakob H, Greinacher A, Peters J. Disseminated intravascular clotting associated with Fc-receptor IIa-mediated platelet activation in a patient with endocarditis after aortic valve replacement. Br J Anaesth. 2006;97:630-3.

5. Mannucci PM, Levi M. Prevention and treatment of major blood loss. N Engl J Med. 2007;356:2301-11.

\section{Late perforation of right atrium and aortic root after percutaneous closure of patent foramen ovale}

Gaetano Palma, MD, Felice Rosapepe, MD, PhD, Mariano Vicchio, MD, Veronica Russolillo, MD, Sabato Cioffi, MD, and Carlo Vosa, MD, Naples, Italy

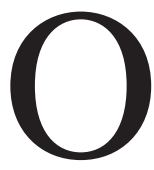

pen heart surgery has been the standard treatment for closure of atrial septal defects (ASDs) for a half century. In the past decade a variety of devices for transcatheter closure of ASDs have become available and an increasing number of patients are treated by this alternative method.

Comparative studies have shown a shorter duration of hospital stay associated with a lower rate of morbidity in patients who underwent percutaneous occlusion than for those treated with classic surgical procedures. ${ }^{1}$ Nevertheless, long-term follow-up has demonstrated excellent outcomes in surgical repair, ${ }^{2}$ although late incidence of device failure and emergency interventions must be analyzed.

We report a case of late perforation of the right atrium and the aortic root by an Amplatzer device (AGA Medical Corp, Golden Valley, Minn) used to close a patent foramen ovale (PFO), necessitating an emergency surgical procedure.

\section{Clinical Summary}

A 28-year-old man with chest pain irradiating to the inferior maxillary bone and interscapular region was brought to the territorial emergency department. Thirteen months earlier, because of a history of cerebral transitory ischemic attacks (TIAs), he had undergone an uncomplicated transcatheter PFO closure with an Amplatzer device at another institution. On clinical examination, the patient was in hemodynamically stable condition, the electrocardiogram showed ST-wave elevation, and the echocardiogram demonstrated an important pericardial effusion without evidence of cardiac tamponade and revealed the right disc of the Amplatzer device leaning toward the aortic root. The transesophageal echocardiogram and computed tomographic scan confirmed that the left atrial disc of the device had perforated the left

From the Department of Cardiothoracic and Respiratory Sciences, Second University of Naples, Naples, Italy.

Received for publication June 7, 2007; accepted for publication June 22, 2007.

Address for reprints: Mariano Vicchio, MD, Via Cassano 150, 80144, Naples, Italy (E-mail: marianovicchio@libero.it).

J Thorac Cardiovasc Surg 2007;134:1054-5

$0022-5223 / \$ 32.00$

Copyright @ 2007 by The American Association for Thoracic Surgery doi:10.1016/j.jtcvs.2007.06.021 atrium and aortic root. The patient was transferred to our institution for the necessary emergency surgical procedure.

The operation was performed through a median sternotomy. Cardiopulmonary bypass was established by ascending aortic and bicaval cannulation. After antegrade cold cardioplegic arrest, we removed the 23-mm Amplatzer device and the adherent wall of the interatrial septum (Figures 1 and 2). A transverse aortotomy was performed to repair the laceration of the aortic root with stitches on pledgets. A Dacron Sauvage patch was used to repair the interatrial septum. The right atrium and the aortotomy were closed directly. The patient had an uncomplicated postoperative recovery and was discharged 6 days later.

\section{Discussion}

Percutaneous transcatheter closure of ASD or PFO has been performed since 1976 as an alternative to conventional surgical repair with various types of mechanical occluder devices. ${ }^{3}$ The Amplatzer septal occluder is a model of such devices and was approved by the Food and Drug Administration in December 2001. A good rate of successful closure has been reported. Nevertheless, cases of late complications necessitating emergency surgical procedures have been described. ${ }^{4}$ Our patient had important anatomic injuries. His hemodynamically stabile condition at the time of surgical repair was a fortunate situation.

Classic open heart surgery remains the standard of care for ASD repair with excellent outcomes since 1954, providing low operative

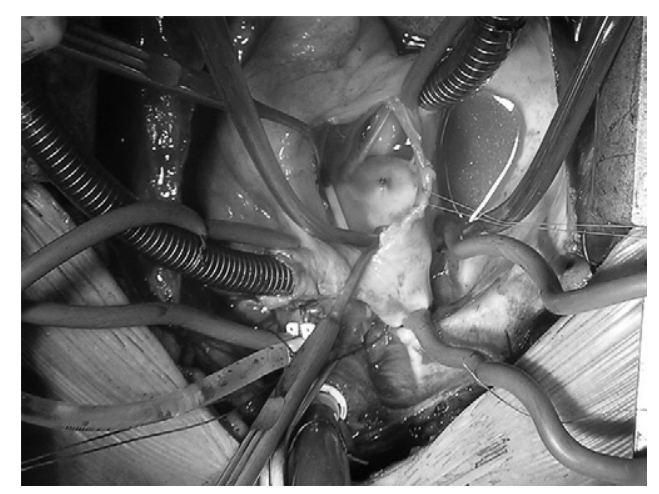

Figure 1. Intraoperative view of the Amplatzer device in the right atrium. 